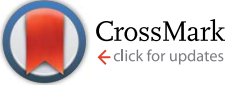

Cite this: RSC Adv., 2016, 6, 66884

\title{
Toward graphene chloride: chlorination of graphene and graphene oxide $\uparrow$
}

\author{
D. Bouša, ${ }^{a}$ J. Luxa, ${ }^{a}$ V. Mazánek, ${ }^{a}$ O. Jankovský, ${ }^{a}$ D. Sedmidubský, ${ }^{a}$ K. Klímová, ${ }^{a}$ \\ M. Pumerab and Z. Sofer ${ }^{\star a}$
}

\begin{abstract}
Halogenated graphene derivatives are interesting due to their outstanding physical and chemical properties. In this paper, we present various methods for the synthesis of chlorinated graphene derivatives from graphene oxide and thermally reduced graphene. We performed exfoliation of graphene oxide in a chlorine atmosphere, plasma assisted exfoliation of graphite oxide using microwave radiation and finally direct chlorination of thermally reduced graphene by liquid chlorine under deep UV irradiation. The influence of the chlorination method on the resulting chlorinated graphenes was investigated by characterization of the graphenes, which was carried out using various techniques, including SEM, SEMEDS, high-resolution XPS, FTIR, STA and Raman spectroscopy. Electrochemical properties were investigated by cyclic voltammetry. Although the graphenes were structurally similar, they involved remarkably different chlorine concentrations. The most highly chlorinated graphene exhibits a chlorine concentration of 11.7 at\%. Chlorinated graphenes with such properties could be used for reversible chlorine storage or as a starting material for further chemical modifications.
\end{abstract}

Received 7th June 2016

Accepted 25th June 2016

DOI: $10.1039 / c 6 r a 14845 j$

www.rsc.org/advances groups used for graphene modifications (for example functionalization by hydrogen atoms ${ }^{9,10}$ or aryl groups via diazonium chemistry ${ }^{\mathbf{1 1 , 1 2}}$ ), halogens are popular for graphene modification. So far, graphene has been modified by all halogen atoms including fluorine, ${ }^{13,14}$ chlorine, ${ }^{15}$ bromine,${ }^{16}$ and iodine. ${ }^{17,18}$ In the reactivity of graphene defects play a crucial role and the theoretical calculations show preferential reaction on defect sites. ${ }^{19}$ The electronic properties of graphene can be also controlled by non-covalent interactions. ${ }^{20}$

Fully chlorinated graphene (chlorographene, $\left[\mathrm{C}_{1} \mathrm{Cl}_{1}\right]_{n}$ ) has been recently studied theoretically, ${ }^{21,22}$ but it has not been experimentally prepared yet. Several methods for graphene chlorination have been reported in literature. Chlorination of graphene can be realized by exfoliation of graphite oxide in the quartz reactor using $\mathrm{Cl}_{2} / \mathrm{N}_{2}$ plasma $\left(100 \mathrm{kPa}, 1000{ }^{\circ} \mathrm{C}\right)$. This method provides graphene with about 2 at\% of chlorine. ${ }^{15}$ Another method is based on photochemical chlorination. In this procedure, graphene flakes supported on $\mathrm{Si} / \mathrm{SiO}_{2}$ substrate were placed in quartz tube reactor filled with a mixture of dry $\mathrm{N}_{2}$ and $\mathrm{Cl}_{2}$ gas. In this setup, graphene flakes were irradiated by UV radiation using xenon lamp. This procedure yields graphene flakes with chlorine content up to 8 at $\% .^{23}$ Partially chlorinated graphene was synthesized in the presence of $\mathrm{CCl}_{4}$ and liquid $\mathrm{Cl}_{2}$ under UV light irradiation. ${ }^{24}$ Precise chlorination of well defined nanographene edges was performed by Yuan-Zhi et al. ${ }^{25}$ using $\mathrm{CCl}_{4}$ solvent, ICl and $\mathrm{AlCl}_{3}$ as catalyst. However, although these methods seem to be effective for chlorination, they can be applied only for surface treatment of graphene or graphene oxide sheets on various supports. Chlorination reaction was also 
performed on the graphene prepared by CVD. An optimized method based on the treatment of graphene with chlorine plasma using an electron cyclotron resonance reactive ion etcher was successfully applied for surface chlorination. ${ }^{26,27}$ These methods usually deal with a complicated and expensive equipment, or can be applied only on a very limited amount of material, like graphene flakes paced on silicon wafer. This strongly limits the application of chlorinated graphene in an industrial scale.

Herein, we prepared chlorinated graphenes by means of three different synthetic methods, which can be simply scaled up on gram or even larger quantities. The synthetic procedures were based on thermal exfoliation of graphene oxide in chlorine atmosphere, chlorine microwave plasma assisted exfoliation of graphene oxide and direct radical chlorination of graphene by reflux in liquid chlorine under deep UV illumination. These three procedures were selected as most suitable and promising for effective synthesis as well as for large scale production of chlorinated graphene. The selection of the chlorination method allowed to control and tune of the chlorine concentration within the graphene. The obtained materials were characterized in detail to evaluate the concentration of chlorine by various analytical methods and to show possible future applications of such material. The obtained results were critically compared with the methods of graphene chlorination reported previously in order to find most suitable and effective method for synthesis of chlorinated graphene with high concentration of $\mathrm{C}-\mathrm{Cl}$ bonds. The simple, effective and large scale synthesis of chlorinated graphene opens a large potential for further covalent modification of graphene due to the high reactivity of $\mathrm{C}-\mathrm{Cl}$ bonds.

\section{Experimental}

\section{Materials}

Pure graphite microparticles $(2-15 \mu \mathrm{m}, 99.9995 \%$, from Alfa Aesar) were used for graphene oxide and graphene synthesis. Sulphuric acid (98\%), nitric acid (68\%), potassium chlorate (99\%), hydrochloric acid (37\%), silver nitrate (99.5\%), barium nitrate $(99.5 \%)$, potassium hydrogen phosphate, potassium dihydrogenphosphate, potassium hexacyanoferrate(II) and $N, N$ dimethylformamide (DMF) were obtained from Penta, Czech Republic. Carbon tetrachloride and hexaammineruthenium(III) chloride were obtained from Sigma-Aldrich, Czech Republic. Chlorine (99.999\%) and nitrogen (99.9999\%) were obtained from Linde Gas a.s. (Czech Republic).

\section{Synthetic procedures}

Graphite oxide prepared according to the Hofmann method is noted as HO-GO.$^{28}$ Sulfuric acid $(98 \%, 87.5 \mathrm{ml})$ and nitric acid $(68 \%, 27 \mathrm{ml})$ were added to a reaction flask (Pyrex beaker with thermometer) containing a magnetic stir bar. The mixture was then cooled by immersion in an ice bath for $30 \mathrm{~min}$. Graphite ( 5 g) was then added to the mixture with vigorous stirring motion to avoid agglomeration and to obtain a homogeneous dispersion. While keeping the reaction flask in the ice bath, potassium chlorate $(55 \mathrm{~g}$ ) was slowly added to the mixture (over a $30 \mathrm{~min}$ period) in order to avoid a sudden increase in temperature and the formation of explosive chlorine dioxide gas. Upon the complete dissolution of potassium chlorate, the reaction flask was then loosely capped to allow the escape of the gas evolved and the mixture was continuously vigorously stirred for 96 hours at room temperature. Upon the reaction completion of the reaction, the mixture was poured into 31 of deionized water and decanted. Graphite oxide was then redispersed in $\mathrm{HCl}$ solution $(5 \%, 3 \mathrm{l})$ to remove sulphate ions and repeatedly centrifuged and redispersed in deionized water until a negative reaction on chloride and sulphate ions (proved by $\mathrm{AgNO}_{3}$ and $\mathrm{Ba}\left(\mathrm{NO}_{3}\right)_{2}$ respectively) was achieved. Graphite oxide slurry was then dried in a vacuum oven at $50{ }^{\circ} \mathrm{C}$ for $48 \mathrm{~h}$ before use.

Thermally reduced graphene (TRG) was prepared by microwave plasma associated reduction. $0.5 \mathrm{~g}$ of HO-GO was placed in a quartz flask in microwave reactor, evacuated and repeatedly flushed with nitrogen and finally with hydrogen. The exfoliation was performed in hydrogen atmosphere. The microwave reactor was evacuated on the base pressure of $1 \mathrm{mbar}$, the hydrogen flow was stopped and the graphite oxide was exfoliated by applying microwave radiation for $30 \mathrm{~s}(1 \mathrm{~kW}, 2.45 \mathrm{GHz})$. The exfoliation procedure was accompanied by a pressure increase to about 20 mbar. The reactor was again evacuated and flushed with the hydrogen gas $\left(50 \mathrm{ml} \mathrm{min}{ }^{-1}\right.$ ) to continuously remove the exfoliation by-products and the microwave radiation was applied for 3 minutes at a pressure of 10 mbar and a continual flow of hydrogen. Application of microwave radiation led to the formation of hydrogen plasma which effectively reduced graphite oxide. The composition of TRG obtained by elemental combustion analysis was 84.79 at $\%$ C, 7.21 at $\% \mathrm{H}, 0.15$ at $\% \mathrm{~N}$ and 7.85 at $\%$ O.

Sample denoted as TRG-Cl was synthesized according to the following procedure. $250 \mathrm{mg}$ of HO-GO was inserted into the quartz reactor. The reactor was flushed several times with high purity $\mathrm{N}_{2}$ and subsequently filled with gaseous $\mathrm{Cl}_{2}$ (flow $500 \mathrm{ml}$ $\mathrm{min}^{-1}$ ). The quartz reactor was then inserted in the furnace preheated on $600{ }^{\circ} \mathrm{C}$ for 10 minutes. Subsequently the reactor was removed from the hot zone and cooled under chlorine atmosphere. Finally, the reactor was flushed again with nitrogen and the resulting sample was kept for further analysis.

Sample denoted as UV-Cl was synthesized according to the following procedure. $250 \mathrm{mg}$ of previously prepared TRG (experimental details above) was placed in a quartz vessel fitted with quartz tube containing $80 \mathrm{~W}$ mercury lamp as a source of deep UV radiation and a dry ice reflux condenser. $100 \mathrm{ml}$ of the liquid chlorine was condensed in the reaction flask and the mixture was subsequently refluxed for 6 hours under UV illumination. Finally the excess chlorine was evaporated and the reactor was flushed with nitrogen until it reached room temperature. The material was subsequently kept in vacuum oven at $50{ }^{\circ} \mathrm{C}$ for 48 hours to remove any physisorbed chlorine. The control experiment was also performed using chlorination of TRG suspension in carbon tetrachloride with chlorine and UV irradiation. $250 \mathrm{mg}$ of TRG was suspended in $250 \mathrm{ml}$ of $\mathrm{CCl}_{4}$ by ultrasonication. The reaction mixture was placed in the photochemical reactor and chlorine was bubbled through the reaction mixture $\left(100 \mathrm{ml} \mathrm{min}^{-1}\right)$ for 6 hours while the reaction 
mixture was irradiated by deep UV mercury lamp $(120 \mathrm{~W})$. Finally the sample was separated by suction filtration, washed with $\mathrm{CCl}_{4}$ and dried in vacuum oven at $50{ }^{\circ} \mathrm{C}$ for 48 hours.

Sample denoted as MW-Cl was synthesized according to the following procedure. $250 \mathrm{mg}$ of HO-GO was inserted into a quartz flask $(500 \mathrm{ml})$ placed in microwave reactor. The reaction flask was then flushed several times by high purity $\mathrm{N}_{2}$. Subsequently, the flask was filled with gaseous $\mathrm{Cl}_{2}$ and the pressure was reduced to 10 mbar. The microwave radiation $(2.45 \mathrm{GHz} ; 1000 \mathrm{~W})$ was applied for 3 minutes while the $\mathrm{Cl}_{2}$ flow

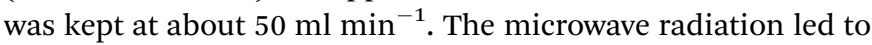
a formation of highly reactive chlorine plasma and, consequently, to exfoliation of HO-GO in the first place and to chlorination of graphene in the second place.

\section{Methods}

The morphology was investigated using scanning electron microscopy (SEM) with a FEG electron source (Tescan Lyra dual beam microscope). The elemental composition and mapping were performed using an energy dispersive spectroscopy (EDS) analyzer (X-MaxN) with a $20 \mathrm{~mm}^{2}$ SDD detector (Oxford instruments) and AZtecEnergy software. To conduct the measurements, the samples were placed on a carbon conductive tape. SEM and SEM-EDS measurements were carried out using a $10 \mathrm{kV}$ electron beam. For the STEM microscopy, sample suspension in iso-propanol $\left(1 \mathrm{mg} \mathrm{ml}^{-1}\right)$ was drop casted onto 200 mesh carbon/Formvar TEM grid and dried at room temperature.

Combustible elemental analysis ( $\mathrm{CHN}-\mathrm{O})$ was performed using a PE 2400 Series II CHNS/O Analyzer (Perkin Elmer, USA). The instrument was used in CHN operating mode (the most robust and interference-free mode) to convert the sample elements to simple gases $\left(\mathrm{CO}_{2}, \mathrm{H}_{2} \mathrm{O}\right.$ and $\left.\mathrm{N}_{2}\right)$. The $\mathrm{PE} 2400$ analyzer performed combustion, reduction, homogenization of product gases, separation and detection automatically. An MX5 microbalance (Mettler Toledo) was used for precise weighing of the samples (1.5-2.5 mg per single sample analysis). Using this procedure, the accuracy of CHN determination is better than $0.30 \%$ abs. The internal calibration was performed using an $\mathrm{N}$ fenyl urea. To measure chlorine concentration, the samples were decomposed for analysis according to the Schöniger method. An exact amount of sample ( $c a .10 \mathrm{mg}$ ) was wrapped in ash-free paper, burned in pure oxygen atmosphere and leached out with deionized water. The $\mathrm{Cl}^{-}$ions formed were titrated with a solution of $\mathrm{Hg}\left(\mathrm{NO}_{3}\right)_{2}$ using sodium nitroprusside as an indicator.

High resolution X-ray photoelectron spectroscopy (XPS) was performed using an ESCAProbeP spectrometer (Omicron Nanotechnology Ltd, Germany) with a monochromatic aluminium X-ray radiation source $(1486.7 \mathrm{eV})$. Wide-scan surveys of all elements were performed, with subsequent high-resolution scans of the $\mathrm{C} 1 \mathrm{~s}, \mathrm{O}$ 1s and halogen peaks. Relative sensitivity factors were used to evaluate the carbon-tooxygen $(\mathrm{C} / \mathrm{O})$ ratios from the survey spectra. The samples were placed in a conductive carrier made from a high purity silver bar.
InVia Raman microscope (Renishaw, England) was used for Raman spectroscopy in backscattering geometry with a CCD detector. Nd-YAG laser $(532 \mathrm{~nm})$ with a $50 \times$ magnification objective was used for the measurements. Instrument calibration was achieved using a silicon reference which gave the optimal peak position at $520 \mathrm{~cm}^{-1}$ and a resolution less than 1 $\mathrm{cm}^{-1}$. To ensure a sufficiently strong signal and to avoid radiation damage of the samples, the laser power $2.5 \mathrm{~mW}$ was used for these measurements. The samples were suspended in deionized water $\left(1 \mathrm{mg} \mathrm{ml}^{-1}\right)$ and ultrasonicated for $10 \mathrm{~min}$. The suspension was deposited on a small piece of silicon wafer and dried.

The FT-IR spectroscopy was performed using iS50R spectrometer (Thermo Scientific; USA). The specular reflectance spectra were measured by SMART SAGA attachment. A gold coated silicon wafer with drop-casted chlorinated graphene samples was used for the measurement. The drop-casting was performed using sample suspension in iso-propanol with concentration of $1 \mathrm{mg} \mathrm{ml}^{-1}$.

Thermal behaviour was analysed by simultaneous thermal analysis (STA). The DTA and TG curves were recorded simultaneously on the Linseis STA PT1600 apparatus at a heating rate of $10{ }^{\circ} \mathrm{C} \min ^{-1}$ from ambient temperature to $1000{ }^{\circ} \mathrm{C}$ in a dynamic synthetic air atmosphere $\left(50 \mathrm{~cm}^{3} \mathrm{~min}^{-1} ; 20\right.$ vol\% $\mathrm{O}_{2}$, 80 vol\% $\mathrm{N}_{2}$ ).

The measurements of zeta-potential were performed on Malvern Zetasizer Nano ZS. The measurement was performed at $\mathrm{pH}=7.0$ in $50 \mathrm{mmol} \mathrm{l}^{-1}$ PBS solution. A suspension of modified TRG with a concentration of $1 \mathrm{mg} \mathrm{ml}^{-1}$ in PBS was used for the measurement.

Electrochemical characterization was performed by cyclic voltammetry using a PGSTAT204 (Metrohm Autolab B.V., The Netherlands) with a three electrode set-up. The glassy carbon working electrode (GC), platinum auxiliary electrode (Pt) and $\mathrm{Ag} / \mathrm{AgCl}$ reference electrode were obtained from Metrohm Autolab B.V. (The Netherlands). Graphene was dispersed in DMF $\left(1 \mathrm{mg} \mathrm{ml}^{-1}\right)$ and $1.5 \mu \mathrm{l}$ of this suspension was evaporated on the glass carbon working electrode for the cyclovoltammetric measurements. All potentials stated in the following section were measured against the $\mathrm{Ag} / \mathrm{AgCl}$ reference electrode. To measure the inherent electrochemistry, a phosphate buffer solution (PBS, $50 \mathrm{mmol} \mathrm{l}^{-1}, \mathrm{pH}=7.2$ ) was used as the supporting electrolyte. The HET rate was measured using a 10 $\mathrm{mmol} \mathrm{l}^{-1} \mathrm{~K}_{4}\left[\mathrm{Fe}(\mathrm{CN})_{6}\right]$ and $10 \mathrm{mmol} \mathrm{l}^{-1}\left[\mathrm{Ru}\left(\mathrm{NH}_{3}\right)_{6}\right] \mathrm{Cl}_{3}$ as a redox probe, with a $50 \mathrm{mmol} \mathrm{l}^{-1} \mathrm{PBS}$ solution as the supporting electrolyte. The electrochemical capacitance was measured in $50 \mathrm{mmol} \mathrm{l}^{-1}$ PBS solution with scan rate in the range of 5-500 $\mathrm{mV} \mathrm{s}^{-1}$.

\section{Results and discussion}

Graphite oxide as well as thermally reduced graphene was used for the synthesis of chlorinated graphene. The thermally reduced graphene, used for chlorination by elemental chorine under UV irradiation, was prepared by hydrogen plasma assisted microwave exfoliation of graphite oxide. Since several methods for the $\mathrm{C}-\mathrm{Cl}$ bond formation on graphene have been published in literature, we performed several syntheses of 
chlorinated graphene in order to develop new methods for large scale and effective chlorination as well as to optimize and to evaluate those previously reported. We chose the synthetic procedures on the base of their scalability for large production and also on the efficiency of $\mathrm{C}-\mathrm{Cl}$ bond formation. We performed exfoliation of graphite oxide in chlorine atmosphere at a relatively low temperature in order to compromise the stability of $\mathrm{C}-\mathrm{Cl}$ bond and increase of chlorine reactivity (sample TRG$\mathrm{Cl}$ ). The second method was based on chlorine plasma assisted exfoliation of graphite oxide generated by microwave radiation (sample $\mathrm{MW}-\mathrm{Cl}$ ) and finally the direct chlorination of thermally reduced graphene was performed by liquid chlorine under deep UV irradiation which led to a formation of highly reactive chlorine radicals (UV-Cl). The obtained samples were characterized in detail using electron microscopy for morphology evaluation, elemental combustion analysis, EDS, XPS and FT-IR spectroscopy for measurement of composition, element distribution and bonding character. The structure and thermal stability was further investigated using Raman spectroscopy and simultaneous thermal analysis in various atmospheres. The electrochemical properties were evaluated using cyclic voltammetry using inner and outer sphere redox probes.

The morphology of all chlorinated graphenes was studied by scanning electron microscopy (SEM) at various magnifications. All samples exhibit a platelet structure typical for graphenebased materials. None of the chlorination methods was thus able to change graphene typical morphology as no obvious differences can be seen between the samples (Fig. 1A). Additionally, we performed scanning transmission electron microscopy (STEM) measurements (Fig. 1B). All chlorinated graphenes exhibited a wrinkled structure where the observed shapes represented agglomerates of the individual chlorinated graphene sheets. Defects on the edges of graphene sheets
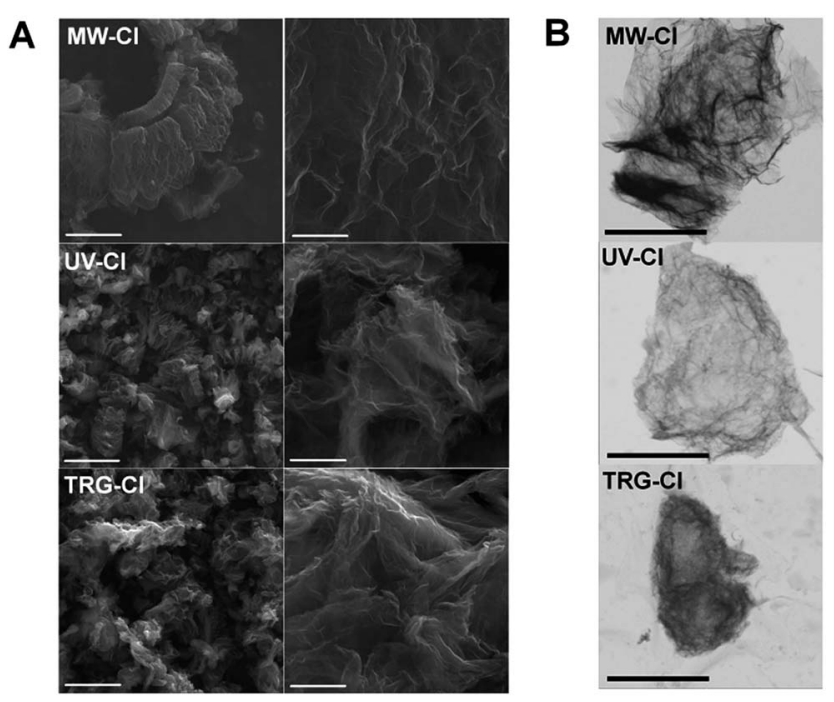

Fig. 1 (A) SEM micrographs of chlorinated graphenes. The scale bars for images are $5 \mu \mathrm{m}$ (left images) and $1 \mu \mathrm{m}$ (right images) and (B) STEM micrographs of chlorinated graphenes. The scale bars for images are $2 \mu \mathrm{m}$. indicating the harassment condition of its synthesis can be observed on the sample TRG-Cl.

In order to prove the homogeneous distribution of chlorine in the samples, energy dispersive spectroscopy coupled with scanning electron microscopy (SEM-EDS) was used. The obtained elemental composition showed that the amount of chlorine varies significantly depending on the used synthetic procedure (Table 1). The highest amount of chlorine (2.6 at\%) was determined in TRG-Cl sample while the lowest (0.7 at\%) for MW-Cl sample. Thus, according to SEM-EDS measurement chlorine content decreased in the order UV-Cl > TRG-Cl > MWCl. In addition, small amounts of Si (less than 0.1 at\%) originating from graphite material used for graphite oxide synthesis were detected.

Since the EDS spectroscopy gives the most reliable results for compact and flat samples, the obtained results are suitable only for trend orientation. The $\mathrm{C} / \mathrm{O}$ ratios, serving as indicators of reduction degree, are summarized in Table 3 and will be discussed later.

Elemental distribution maps (Fig. 2) show that the distribution of chlorine over the measured area of the sample is homogenous. Such distribution of chlorine indicates that the reaction took place not only on the reactive edges of graphene sheets but also on significantly less reactive basal planes. Thus, all chlorination methods we used can provide homogenously modified graphene with uniform chlorine distribution.

To confirm the elemental composition of the chlorinated graphenes combustion elemental analysis ( $\mathrm{CHN}-\mathrm{O})$ was used. This method can also provide information about hydrogen content which is undetectable by SEM-EDS and XPS. The results

Table 1 Elemental composition (at\%) of chlorinated graphenes obtained from SEM-EDS

\begin{tabular}{llll}
\hline Sample & C & O & Cl \\
\hline MW-Cl & 93.7 & 5.5 & 0.7 \\
UV-Cl & 90.0 & 7.4 & 2.6 \\
TRG-Cl & 88.4 & 9.7 & 1.9
\end{tabular}

Table 2 Results (at\%) of elemental combustion analysis ( $\mathrm{CHN}-\mathrm{O}$ )

\begin{tabular}{llrlll}
\hline Sample & C & O & Cl & H & N \\
\hline MW-Cl & 84.4 & 5.8 & 3.4 & 4.8 & 1.6 \\
UV-Cl & 75.2 & 11.8 & 3.1 & 9.8 & 0.2 \\
TRG-Cl & 77.7 & 7.8 & 9.0 & 5.5 & -
\end{tabular}

Table $3 \mathrm{C} / \mathrm{O}$ ratios calculated from SEM-EDS, CHN-O and XPS analysis

\begin{tabular}{lccr}
\hline Sample & SEM-EDS & CHN-O & XPS \\
\hline MW-Cl & 17.04 & 14.53 & 14.49 \\
UV-Cl & 12.16 & 6.37 & 7.41 \\
TRG-Cl & 9.11 & 9.96 & 12.97
\end{tabular}




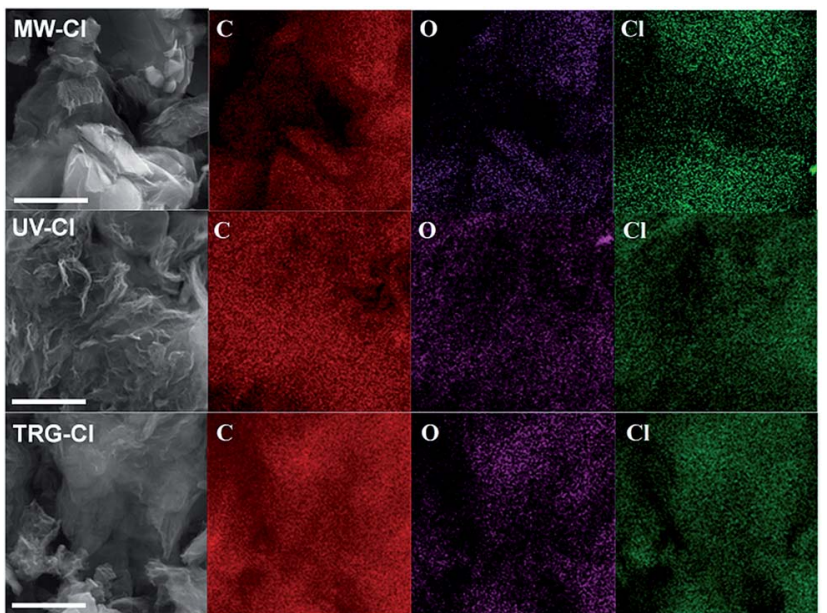

Fig. 2 SEM-EDS element distribution maps of chlorinated graphenes. The scale bars for images are $5 \mu \mathrm{m}$.

of elemental analysis were different from those obtained by SEM-EDS (Table 2) and XPS due to the differences in analytical method. EDS needs compact flat samples for accurate analysis while XPS is a surface sensitive method which gives the results from the first few nanometers of the surface. $\mathrm{CHN}-\mathrm{O}$ analysis detected the highest amount of chlorine (9.0 at\%) for TRG-Cl sample while the lowest value (3.1 at $\%$ ) was achieved for UV$\mathrm{Cl}$ sample. The sequence of the chlorine content according to $\mathrm{CHN}-\mathrm{O}$ analysis is TRG-Cl $>\mathrm{MW}-\mathrm{Cl}>\mathrm{UV}-\mathrm{Cl}$. The $\mathrm{Cl}$ concentration in TRG-Cl is higher than in $\mathrm{MW}-\mathrm{Cl}$ which is consistent with SEM-EDS results. On the other side, UV-Cl sample exhibits the lowest $\mathrm{Cl}$ concentration according to $\mathrm{CHN}-\mathrm{O}$ analysis which is different from EDS and XPS (highest $\mathrm{Cl}$ concentration for UV$\mathrm{Cl}$ ). This can be caused by incomplete sample combustion using Schöniger method for elemental analysis of chlorine as it is well known that the halogenated hydrocarbons act as flame retardants. ${ }^{29}$ The $\mathrm{C} / \mathrm{O}$ ratios were calculated from the results of the $\mathrm{CHN}-\mathrm{O}$ analysis (Table 3). As mentioned above, $\mathrm{C} / \mathrm{O}$ ratios act as an indicator of the degree of reduction (a higher $\mathrm{C} / \mathrm{O}$ ratio indicates a higher degree of reduction). According to $\mathrm{CHN}-\mathrm{O}$ and XPS analysis MW-Cl was the sample with the highest degree of reduction followed by TRG-Cl and UV-Cl.

Due to differences in chlorine content measured by SEMEDS and CHN-O, X-ray photoelectron spectroscopy (XPS) was used to determine the surface chemical composition of the chlorinated graphenes and also to obtain the information about the bonding of carbon and chlorine. The XPS survey spectra (Fig. 3A) clearly show the presence of $\mathrm{C} 1 \mathrm{~s}, \mathrm{O} 1 \mathrm{~s}, \mathrm{Cl} 2 \mathrm{~s}$ and $\mathrm{Cl} 2 \mathrm{p}$ peaks in all samples. The $\mathrm{Cl} 2 \mathrm{p}$ peak was found to be at $200.5 \mathrm{eV}$, $\mathrm{Cl} 2 \mathrm{~s}$ at $271.3 \mathrm{eV}, \mathrm{C} 1 \mathrm{~s}$ at $285.5 \mathrm{eV}$ and $\mathrm{O} 1 \mathrm{~s}$ at $533.2 \mathrm{eV}$. These survey spectra were used to calculate the concentration of $\mathrm{C}, \mathrm{O}$ and $\mathrm{Cl}$ (Table 4) as well as the $\mathrm{C} / \mathrm{O}$ ratio (Table 3). The highest content of chlorine was detected in TRG-Cl sample. Chlorine concentration decreases in the order UV-Cl $>$ TRG-Cl $>$ MW-Cl according to XPS. This trend is the same as the one measured by SEM-EDS indicating an incomplete sample combustion during chlorine analysis by combustion method which resulted in an underestimated concentration of chlorine. Thus, the correct $\mathrm{Cl}$ concentration trend should be UV-Cl $>$ TRG-Cl $>$ MW$\mathrm{Cl}$. The results of SEM-EDS, CHN-O and XPS confirmed a successful chlorination of the starting carbon material by all synthetic procedures. The most effective method for chlorination is based on direct radical chlorination of thermally reduced graphene by liquid chlorine under UV radiation. This method gives a chlorine concentration of 11.7 at $\%$ which corresponds to almost two chlorine atom per one $\mathrm{C} 6$ graphene motive. The thermal exfoliation in chlorine atmosphere is also a highly effective method yielding 9.2 at $\%$ of $\mathrm{Cl}$ which is also close to 2 chlorine atoms per one $\mathrm{C} 6$ motive of graphene. By contrast, the microwave exfoliation was found as the least effective method giving only 2.8 at $\%$ of $\mathrm{Cl}$. The obtained concentrations are lower compared to the method reported by Rao et al. using $\mathrm{CCl}_{4} / \mathrm{Cl}_{2}$ radical chlorination of graphene. ${ }^{24}$ In order to check these experimental results, we also performed the synthesis under comparable conditions (see the Experimental section). The chlorination was performed using $\mathrm{Cl}_{2}$ flow $\left(100 \mathrm{ml} \mathrm{min}^{-1}\right)$ through a suspension of graphene in $\mathrm{CCl}_{4}(125 \mathrm{~W}$ high pressure mercury lamp immersed in reaction mixture) keep as a control experiment. This sample contained a significantly lower concentration of chlorine compared to direct chlorination with liquid chlorine and also to the reported values $(77.7$ at $\%$ C, 3.3
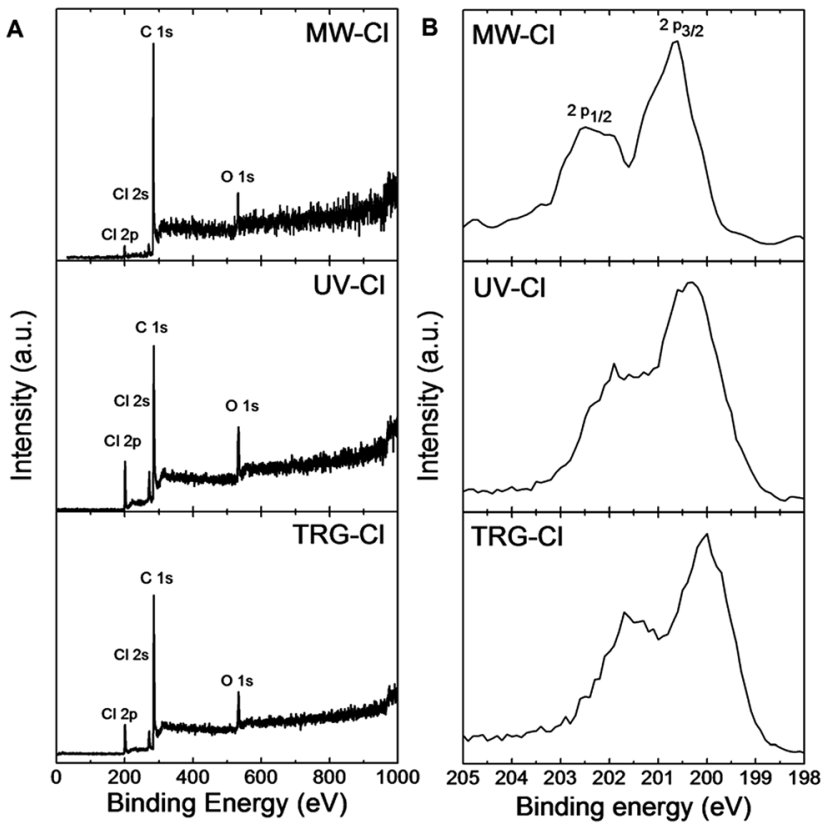

Fig. 3 (A) XPS survey spectra of chlorinated graphenes and (B) detail HR-XPS spectra of $\mathrm{Cl} 2 \mathrm{p}$ peak of chlorinated graphenes.

Table 4 Elemental composition (at\%) of chlorinated graphenes obtained from XPS survey spectra

\begin{tabular}{llcc}
\hline Sample & C & O & Cl \\
\hline MW-Cl & 90.96 & 6.28 & 2.76 \\
UV-Cl & 77.8 & 10.5 & 11.7 \\
TRG-Cl & 84.3 & 6.5 & 9.2
\end{tabular}


at\% $\mathrm{Cl}, 9.2$ at\% $\mathrm{O}, 9.8$ at\% $\mathrm{H}$ and 0.0 at\% $\mathrm{N}$ by elemental combustion analysis). This may indicate a significant contribution of physisorbed chlorine to the results reported in literature. High resolution XPS spectra of $\mathrm{Cl} 2 \mathrm{p}$ peak are shown in Fig. 3B. The $\mathrm{Cl} 2 \mathrm{p}$ peak composed of two peaks, $\mathrm{Cl} 2 \mathrm{p}_{1 / 2}$ at 202.2 $\mathrm{eV}$ and $\mathrm{Cl} 2 \mathrm{p}_{3 / 2}$ at $200.6 \mathrm{eV}$ which are assigned to $\mathrm{C}-\mathrm{Cl}$ bonds. Position of those peaks indicates a successful formation of $\mathrm{C}-\mathrm{Cl}$ bonds.

A detailed peak-fitting analysis of the $\mathrm{C}$ 1s peak for all chlorinated graphenes is shown in Fig. 4A. High resolution $\mathrm{C}$ 1s spectra were fitted to quantitatively differentiate the six different carbon bonding states: $\mathrm{C}-\mathrm{C}(284.5 \mathrm{eV}), \mathrm{C}=\mathrm{C}(285.5$ $\mathrm{eV}), \mathrm{C}-\mathrm{O} / \mathrm{C}-\mathrm{Cl}(286.2 \mathrm{eV}), \mathrm{C}=\mathrm{O}(287.4 \mathrm{eV}), \mathrm{O}-\mathrm{C}=\mathrm{O}(288.7 \mathrm{eV})$ and $\pi-\pi *$ interaction $(290.8 \mathrm{eV})$. The $\mathrm{C}-\mathrm{O}$ and $\mathrm{C}-\mathrm{Cl}$ bonds have very similar binding energies: $\mathrm{C}-\mathrm{O}$ has been reported at 286.2 $\mathrm{eV}$ and $\mathrm{C}-\mathrm{Cl}$ at $286.6 \mathrm{eV} .^{30}$ Results of the $\mathrm{C} 1 \mathrm{~s}$ peak deconvolution are summarized in Table 5 . The following trend in concentration of $\mathrm{C}-\mathrm{O} / \mathrm{C}-\mathrm{Cl}$ bonds was determined from high resolution $\mathrm{C}$ 1s peak is as follow: UV-Cl $>$ TRG-Cl $>\mathrm{MW}-\mathrm{Cl}$. This trend is consistent with those obtained from SEM-EDS and survey XPS spectra.

To obtain more structural information about chlorinated graphenes Raman spectroscopy measurement was applied (Fig. 4B). The Raman spectra are dominated by two main peaks denoted as D and G. The D band located at $1360 \mathrm{~cm}^{-1}$ is associated with defects in the regular network of $\mathrm{sp}^{2}$ hybridized
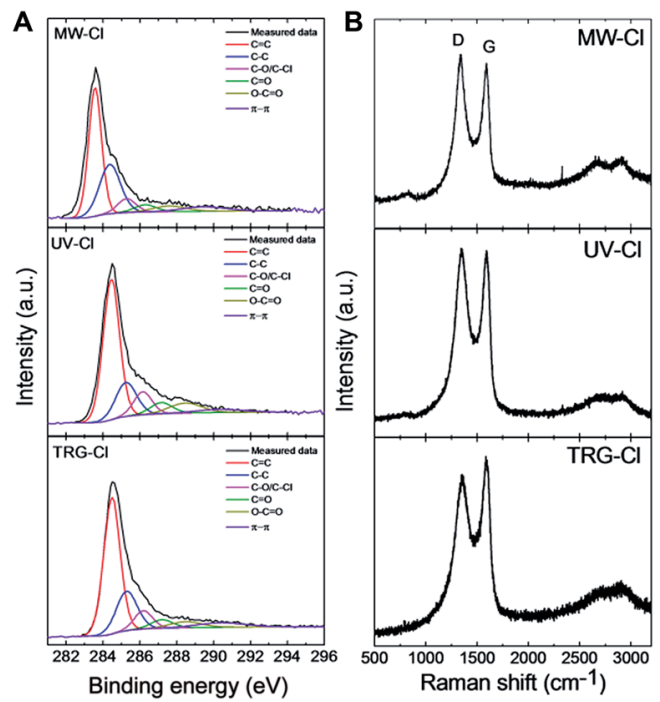

Fig. 4 (A) High resolution XPS details of $C$ 1s peak of chlorinated graphenes and (B) Raman spectra of chlorinated graphenes.

Table 5 The results of $C$ 1s peak deconvolution of chlorinated graphene

\begin{tabular}{lllllll}
\hline Sample & $\begin{array}{l}\mathrm{C}=\mathrm{C} \\
(\%)\end{array}$ & $\begin{array}{l}\mathrm{C}-\mathrm{C} \\
(\%)\end{array}$ & $\begin{array}{l}\mathrm{C}-\mathrm{O} / \mathrm{C}-\mathrm{Cl} \\
(\%)\end{array}$ & $\begin{array}{l}\mathrm{C}=\mathrm{O} \\
(\%)\end{array}$ & $\begin{array}{l}\mathrm{O}-\mathrm{C}=\mathrm{O} \\
(\%)\end{array}$ & $\begin{array}{l}\pi-\pi \\
(\%)\end{array}$ \\
\hline MW-Cl & 47.41 & 29.60 & 7.23 & 4.64 & 5.43 & 5.69 \\
UV-Cl & 55.33 & 17.04 & 10.05 & 6.01 & 7.93 & 3.65 \\
TRG-Cl & 55.85 & 20.55 & 8.33 & 4.79 & 4.98 & 5.50
\end{tabular}

carbon atoms and the presence of $\mathrm{sp}^{3}$ hybridized carbon atoms. ${ }^{31}$ The $\mathrm{G}$ band located at $1580 \mathrm{~cm}^{-1}$ is associated with the vibration of $\mathrm{sp}^{2}$ hybridized carbon atoms in planar graphene skeleton. ${ }^{32}$ In addition, 2D band at $2780 \mathrm{~cm}^{-1}$ and $\mathrm{D}^{\prime \prime}$ band located around $2950 \mathrm{~cm}^{-1}$ are also visible in Fig. 4B; however, their intensity is low. ${ }^{33}$ The $I_{\mathrm{D}} / I_{\mathrm{G}}$ band intensity ratio is used for comparison of defects and disorder density in the modified graphenes and also for detection of $\mathrm{sp}^{3}$ hybridized carbon atoms concentration. The $I_{\mathrm{D}} / I_{\mathrm{G}}$ ratios were $1.09,1.03$ and 0.90 for MW-Cl, UV-Cl and TRG-Cl, respectively. This indicates a high degree of defects formed by chlorine plasma during the chlorination/exfoliation process. Since the values of $I_{\mathrm{D}} / I_{\mathrm{G}}$ ratio are not clearly correlated with the concentration of chlorine or oxygen, the obtain results shows a dominant influence of disorder on the $I_{\mathrm{D}} / I_{\mathrm{G}}$ ratio. Since the defect play important role in the reactivity of graphene, ${ }^{19}$ low concentration of chlorine in MW-Cl sample originate from low partial pressure in the reactor which is necessary for formation of chlorine plasma.

The thermal stability of the chlorinated graphenes was investigated under dynamic air atmosphere. STA measurement (Fig. 5) exhibit exothermic peak located between 550 and $650{ }^{\circ} \mathrm{C}$ originating from combustion of chlorinated graphene. Significant differences can be observed between the individual samples. The MW-Cl sample shows only one very narrow peak of combustion with an onset at $580^{\circ} \mathrm{C}$ and a maximum at $595{ }^{\circ} \mathrm{C}$ UV-Cl, however the weight change on TG signal is observable from $450{ }^{\circ} \mathrm{C}$. The thermal behaviour of UV-Cl sample is significantly different, where an additional exothermic peak associated with mass change at $260{ }^{\circ} \mathrm{C}$ can be indicated. This effect can be associated with a partial loss of chlorine. The combustion peak is observed at $520{ }^{\circ} \mathrm{C}$ with a maximum at $550{ }^{\circ} \mathrm{C}$. A significantly broader exothermic peak is observed on TRG-Cl sample, with the changes in heat flow associated with a weight change observable from $400{ }^{\circ} \mathrm{C}$, however, the sharp maximum of the combustion process is observed at significantly higher temperature at $670{ }^{\circ} \mathrm{C}$. From this observation we can conclude that in the thermal stability of chlorinated graphene not only concentration of chlorine, but also the structure of chlorinated graphene and the method of its synthesis play a significant role. The thermal behaviour is notably different in argon atmosphere, since no combustion can take place (Fig. SI1 $\dagger$ ). The main weight changes are observed at temperatures exceeding $600{ }^{\circ} \mathrm{C}$ indicating high thermal stability of $\mathrm{C}-\mathrm{Cl}$ bonds. Also the highest weight changes are observed for samples with the highest chlorine content (UV-Cl and TRG-Cl). The slight changes observed below this temperature can be associated with a decomposition of the remaining oxygen functionalities as well as with a partial decomposition of $\mathrm{C}-\mathrm{Cl}$ bonds and a desorption of adsorbed chlorine. This effect is most significant for UV-Cl sample, where the exothermic peak was observed also in air atmosphere at temperatures below 300 ${ }^{\circ} \mathrm{C}$.

In order to definitively prove the presence of $\mathrm{C}-\mathrm{Cl}$ bonds FTIR spectra were collected using specular reflectance technique (Fig. 6). Due to the high absorption coefficient of graphene in the IR region only weak intensity of bands was observed. Nevertheless, we were able to assign $\mathrm{C}-\mathrm{Cl}$ vibration band at 824 


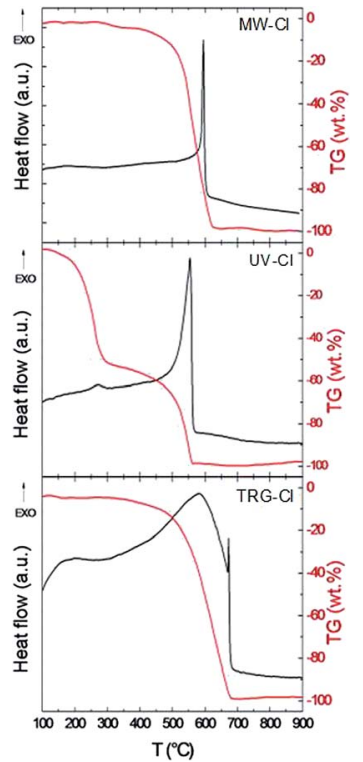

Fig. 5 STA measurement of chlorinated graphenes in air atmosphere.

$\mathrm{cm}^{-1}$. This value is close to the one reported at $790 \mathrm{~cm}^{-1} \cdot{ }^{19}$ Also, it was theoretically calculated that $\mathrm{C}-\mathrm{Cl}$ has only one IR active vibration mode $\left(\mathrm{A}_{2 \mathrm{u}}\right)$ at $850 \mathrm{~cm}^{-1} \cdot{ }^{16}$ We also observed other bands in the IR spectra which correspond to the remaining oxygen functionalities. A broad band around $1375 \mathrm{~cm}^{-1}$ is related to the $\mathrm{C}-\mathrm{O}$ vibration modes. The characteristic vibration of graphene skeleton $(\mathrm{C}=\mathrm{C})$ can be seen approximately at $1660 \mathrm{~cm}^{-1}$.

Further characteristics of the chlorinated graphenes were obtained by measurement of zeta-potential. Different concentration of chlorine has a significant effect on the zeta-potential and thus on the aqueous solution processability of the chlorinated graphenes. All samples exhibit non-zero zeta-potential values (Fig. 7) which are in relation with the chlorine concentration. The zeta-potential trend is similar to the chlorine

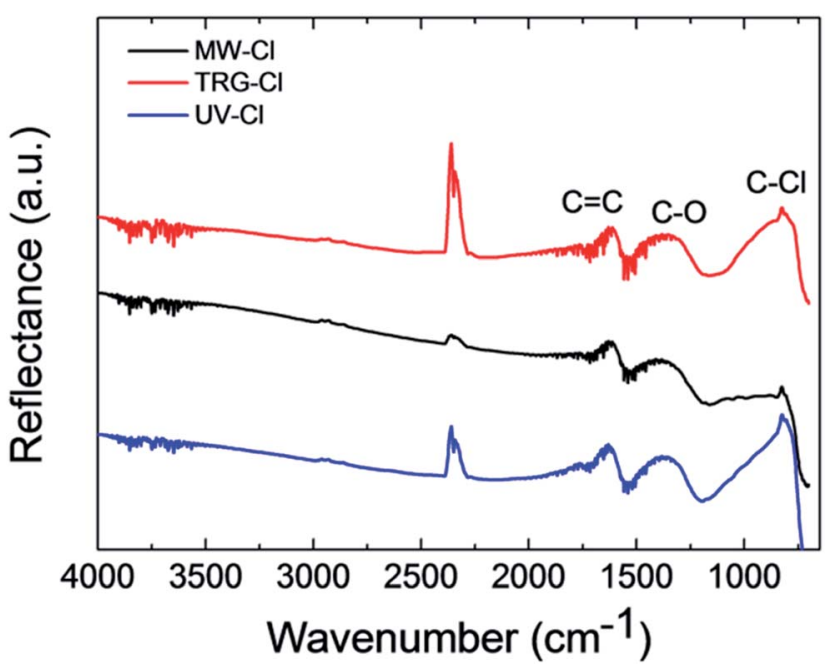

Fig. 6 FT-IR spectra of chlorinated graphenes measured using specular reflectance technique.

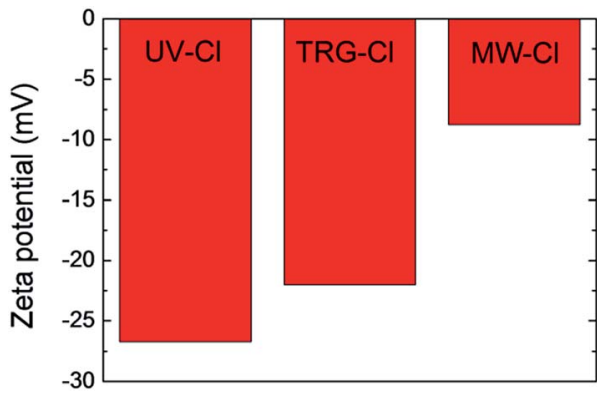

Fig. 7 Zeta-potential of chlorinated graphenes.

concentration trend obtained by EDS and XPS. The higher the concentration of chlorine the more negative zeta-potential is detected. This observation can be useful during preparation of graphene devices by solution-based techniques. The zetapotential value correlates with the chlorine concentration and the lowest zeta-potential is observed for sample with the highest concentration of chlorine. This effect can be attributed to the high electronegativity of chlorine atoms.

Electrochemical properties of the chlorinated graphenes were investigated by measurement of inherent electrochemistry in phosphate buffer solution $\left(c(\mathrm{PBS})=0.05 \mathrm{~mol} \mathrm{l}^{-1} ; \mathrm{pH}=7.2\right)$. All samples exhibit reduction peaks which can be seen on both, cathodic and anodic direction cyclic voltammetry scan (Fig. SI $2 \dagger$ ). Those peaks indicate the presence of residual oxygen containing groups (peroxy, epoxy, aldehyde) ${ }^{34}$ which are reduced in the first cycle. The reduction peak starting at about $-0.5 \mathrm{~V}$ can be seen for both, cathodic and anodic direction of the cyclic voltammetry scan. In the case of the MW-Cl sample, the reduction peak starting at $-0.4 \mathrm{~V}$ is significantly larger for the cathodic direction cyclic voltammetry scan. The reduction peak in the first cycle originates from the reduction of remaining oxygen functionalities as well as from traces of the adsorbed chlorine.

Heterogeneous electron transport (HET) rates of the chlorinated graphenes were studied using $\left[\mathrm{Fe}(\mathrm{CN})_{6}\right]^{3-/ 4-}$ redox probe (Fig. 8A). HET rate was estimated from the peak-to-peak separation value of the oxidation and reduction potential of $\left[\mathrm{Fe}(\mathrm{CN})_{6}\right]^{3-/ 4-}$ on chlorinated graphenes (Table 6). In general, the lower the peak-to-peak separation value the higher the heterogeneous electron transfer rate. The HET rates increase in the following order: MW-Cl > UV-Cl > TRG-Cl. However, the
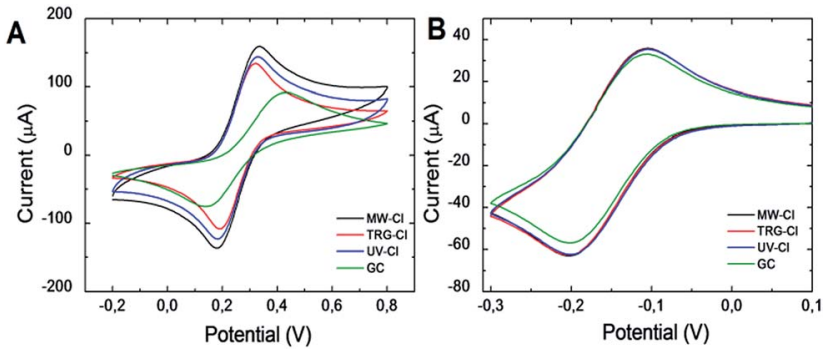

Fig. 8 The cyclic voltammograms of chlorinated graphenes. (A) $\left[\mathrm{Fe}(\mathrm{CN})_{6}\right]^{3-14-}$ and $(\mathrm{B})\left[\mathrm{Ru}\left(\mathrm{NH}_{3}\right)_{6}\right]^{3+/ 2+}$ was used as redox probe $(\mathrm{C}=$ $0.01 \mathrm{~mol} \mathrm{l}^{-1}$ in PBS). 
Table 6 Oxidation and reduction potentials of $\left[\mathrm{Fe}(\mathrm{CN})_{6}\right]^{3-/ 4-}$ redox probe at chlorinated graphenes and corresponding peak-to-peak separation values

\begin{tabular}{llll}
\hline Sample & $E_{\text {ox }}(\mathrm{mV})$ & $E_{\text {red }}(\mathrm{mV})$ & $\Delta E(\mathrm{mV})$ \\
\hline MW-Cl & 334 & 180 & 154 \\
UV-Cl & 329 & 187 & 142 \\
TRG-Cl & 320 & 190 & 130 \\
GC & 432 & 138 & 294
\end{tabular}

Table 7 Oxidation and reduction potentials of $\left[\mathrm{Ru}\left(\mathrm{NH}_{3}\right)_{6}\right]^{2+/ 3+}$ redox probe at chlorinated graphenes and corresponding peak-to-peak separation values

\begin{tabular}{llll}
\hline Sample & $E_{\text {ox }}(\mathrm{mV})$ & $E_{\text {red }}(\mathrm{mV})$ & $\Delta E(\mathrm{mV})$ \\
\hline MW-Cl & -105 & -203 & 98 \\
UV-Cl & -104 & -204 & 100 \\
TRG-Cl & -103 & -201 & 98 \\
GC & -106 & -202 & 96
\end{tabular}

differences between samples are relatively small indicating a negligible effect of chlorine concentration on the HET rate. To further understand HET rate behavior on the chlorinated graphenes we performed cyclic voltammetry measurement using $\left[\mathrm{Ru}\left(\mathrm{NH}_{3}\right)_{6}\right]^{3+/ 2+}$ redox probe (Fig. 8B). Unlike $\left.\mathrm{Fe}(\mathrm{CN})_{6}\right]^{3-/ 4-}$, $\left[\mathrm{Ru}\left(\mathrm{NH}_{3}\right)_{6}\right]^{3+/ 2+}$ is known to be insensitive to surface functional groups (Table 7). ${ }^{35}$ Chlorinated graphenes do not exhibit differences in oxidation or reduction potentials of $\left[\mathrm{Ru}\left(\mathrm{NH}_{3}\right)_{6}\right]^{3+2+}$ redox probe. The results indicate only minimal effect of chlorine concentration on the HET rate for the inner sphere redox probes.

\section{Conclusions}

Three methods for chlorinated graphene synthesis were evaluated using thermal exfoliation of graphene oxide in chlorine atmosphere, chlorine plasma assisted exfoliation and direct chlorination of thermally reduced graphene by radical chlorination in liquid chlorine under UV irradiation. From these methods, the radical chlorination in liquid chlorine and thermal exfoliation in chlorine atmosphere gave the highest concentration of $\mathrm{Cl}, 11.3$ at $\%$ and 9.2 at\%, respectively. The C$\mathrm{Cl}$ bond formation was proved by XPS and FT-IR spectroscopy. The chlorine was homogenously distributed over the graphene surface. The DSC/TG measurements show the stability of chlorinated graphene at temperatures up to $600{ }^{\circ} \mathrm{C}$ in inert atmosphere and good thermal stability in air atmosphere. The inherent electrochemistry showed the presence of traces of adsorbed chlorine which is reduced below $-0.3 \mathrm{~V}$ as well as the remaining electrochemically active oxygen functionalities. The increase of chlorine concentration led to a slight reduction of HET rate using $\left[\mathrm{Fe}(\mathrm{CN})_{6}\right]^{3-14-}$ outer sphere redox probe, however no changes were observed using inner sphere redox probe like $\left[\mathrm{Ru}\left(\mathrm{NH}_{3}\right)_{6}\right]^{2+/ 3+}$. The reported methods can be used for synthesis of chlorinated graphene with controlled concentration of chlorine exceeding previously reported values. These finding bring huge opportunity for further covalent modifications of graphene due to the $\mathrm{C}-\mathrm{Cl}$ bond reactivity.

\section{Acknowledgements}

The project was supported by Czech Science Foundation (GACR No. 15-09001S) and by Specific University Research (MSMT No. 20-SVV/2016). M. P. acknowledges a Tier 2 grant (MOE2013-T21-056; ARC 35/13) from the Ministry of Education, Singapore.

\section{Notes and references}

1 (a) A. K. Geim and K. S. Novoselov, Nat. Mater., 2007, 6, 183191; (b) R. K. Joshi, S. Alwarappan, M. Yoshimura, V. Sahajwalla and Y. Nishina, Appl. Mater. Today, 2015, 1, 1-12.

2 K. I. Bolotin, K. Sikes, Z. Jiang, M. Klima, G. Fudenberg, J. Hone, P. Kim and H. Stormer, Solid State Commun., 2008, 146, 351-355.

3 W. Cai, Y. Zhu, X. Li, R. D. Piner and R. S. Ruoff, Appl. Phys. Lett., 2009, 95, 123115.

4 C. Lee, X. Wei, J. W. Kysar and J. Hone, Science, 2008, 321, 385-388.

5 P. A. Denis and F. Iribarne, Chem.-Eur. J., 2012, 18, 75687574.

6 P. A. Denis, ChemPhysChem, 2013, 14(14), 3271-3277.

7 P. A. Denis, C. P. Huelmo and F. Iribarne, Comput. Theor. Chem., 2014, 1049, 13-19.

8 P. A. Denis and C. P. Huelmo, Carbon, 2015, 87, 106-115.

9 J. O. Sofo, A. S. Chaudhari and G. D. Barber, Phys. Rev. B: Condens. Matter Mater. Phys., 2007, 75, 153401.

10 D. Bouša, J. Luxa, D. Sedmidubský, Š. Huber, O. Jankovský, M. Pumera and Z. Sofer, RSC Adv., 2016, 6, 6475-6485.

11 P. Huang, L. Jing, H. Zhu and X. Gao, Acc. Chem. Res., 2012, 46, 43-52.

12 D. Bouša, M. Pumera, D. Sedmidubský, J. Šturala, J. Luxa, V. Mazánek and Z. Sofer, Nanoscale, 2016, 8, 1493-1502.

13 (a) R. R. Nair, W. Ren, R. Jalil, I. Riaz, V. G. Kravets, L. Britnell, P. Blake, F. Schedin, A. S. Mayorov and S. Yuan, Small, 2010, 6, 2877-2884; (b) T. V. Vineesh, M. A. Nazrulla, S. Krishnamoorthy, T. N. Narayanan and S. Alwarappan, Appl. Mater. Today, 2015, 1, 74-79; (c) H. L. Poh, Z. Sofer, K. Klimova and M. Pumera, J. Mater. Chem. C, 2014, 2, 5198-5207.

14 Z. Sofer, P. Šimek, V. Mazánek, F. Šembera, Z. Janoušek and M. Pumera, Chem. Commun., 2015, 51, 5633-5636.

15 H. L. Poh, P. Šimek, Z. Sofer and M. Pumera, Chem.-Eur. J., 2013, 19, 2655-2662.

16 O. Jankovský, P. Šimek, K. Klimová, D. Sedmidubský, S. Matějková, M. Pumera and Z. Sofer, Nanoscale, 2014, 6, 6065-6074.

17 G. Kalita, K. Wakita, M. Takahashi and M. Umeno, J. Mater. Chem., 2011, 21, 15209-15213.

18 P. Šimek, K. Klímová, D. Sedmidubský, O. Jankovský, M. Pumera and Z. Sofer, Nanoscale, 2015, 7, 261-270.

19 P. A. Denis and F. Iribarne, J. Phys. Chem. C, 2013, 117, 19048-19055. 
20 P. A. Denis and F. Iribarne, J. Phys. Chem. C, 2015, 119, 15103-15111.

21 H. Sahin and S. Ciraci, J. Phys. Chem. C, 2012, 116, 2407524083.

22 M. Yang, L. Zhou, J. Wang, Z. Liu and Z. Liu, J. Phys. Chem. C, 2011, 116, 844-850.

23 B. Li, L. Zhou, D. Wu, H. Peng, K. Yan, Y. Zhou and Z. Liu, ACS Nano, 2011, 5, 5957-5961.

24 K. Gopalakrishnan, K. Subrahmanyam, P. Kumar, A. Govindaraj and C. Rao, RSC Adv., 2012, 2, 1605-1608.

25 Y.-Z. Tan, B. Yang, K. Parvez, A. Narita, S. Osella, D. Beljonne, X. Feng and K. Müllen, Nat. Commun., 2013, 4, 2646.

26 X. Zhang, A. Hsu, H. Wang, Y. Song, J. Kong, M. S. Dresselhaus and T. Palacios, ACS Nano, 2013, 7, $7262-7270$.

27 X. Zhang, T. Schiros, D. Nordlund, Y. C. Shin, J. Kong, M. Dresselhaus and T. Palacios, Adv. Funct. Mater., 2015, 25, 4163-4169.
28 U. Hofmann and E. König, Z. Anorg. Allg. Chem., 1937, 234, 311-336.

29 S. Shaw, Rev. Environ. Health, 2010, 25, 261-306.

30 E. Papirer, R. Lacroix, J.-B. Donnet, G. Nansé and P. Fioux, Carbon, 1995, 33, 63-72.

31 A. W. Musumeci, E. R. Waclawik and R. L. Frost, Spectrochim. Acta, Part A, 2008, 71, 140-142.

32 W.-R. Liu, S.-L. Kuo, C.-Y. Lin, Y.-C. Chiu, C.-Y. Su, H.-C. Wu and C. Hsieh, Open Mater. Sci. J., 2011, 5, 236-241.

33 L. Malard, M. Pimenta, G. Dresselhaus and M. Dresselhaus, Phys. Rep., 2009, 473, 51-87.

34 E. L. K. Chng and M. Pumera, Chem.-Asian J., 2011, 6, 28992901.

35 P. Chen and R. L. McCreery, Anal. Chem., 1996, 68, 39583965. 